\title{
The concurrence of musculoskeletal pain and associated work-related factors: a cross sectional study
}

Rita de Cássia Pereira Fernandes ${ }^{1,2}$, Silvana Maria da Silva Pataro ${ }^{1}$, Roberta Brasileiro de Carvalho ${ }^{1}$ and Alex Burdorf ${ }^{2 *}$ (D)

\begin{abstract}
Background: Several recent studies have described the presence of musculoskeletal complaints, presenting evidence that multisite musculoskeletal pain (MP) is more often present than single-site musculoskeletal pain. However, less is known about determinants of this multimorbidity, particularly, concerning the role of occupational factors and, mainly, what determines single or multisite pain. This study described the associations between pain in different body sites and investigated related factors to MP in workers from Brazil.
\end{abstract}

Methods: A total of 1070 workers (228 women and 842 men), from urban cleaning services and from shoe manufacturers, participated in this cross sectional study (response $97 \%$ ). Interviewer-administered questionnaire included sociodemographic factors, physical and psychosocial work demands, leisure-time activities and musculoskeletal pain which was presence of pain in previous seven days, considering eight body sites and MP, the sum score of all painful sites, varying 0-8. A factor analysis was performed that captured the nine variables of physical exposure into two latent factors. Associations of pain between different body sites were assessed. Cox regression analyses, presenting the prevalence ratio (PR), showed the related factors to MP.

Results: In the previous seven days, $30 \%$ of workers had MP. For all body sites, comorbidity ranged from $72 \%$ to $91 \%$. Having pain in one body site is associated with pain in other site and the associations between proximal sites were stronger than between more distal sites. High exposure to manual material handling and awkward postures ( $P R=1.5,95 \% \mathrm{Cl} 1.1-2.0)$, job strain ( $\mathrm{PR}=1.2,95 \% \mathrm{Cl} 1.0-1.6)$, and low social support $(P R=1.3,95 \% \mathrm{Cl} 1.0-1.7)$ and being woman $(P R=1.7,95 \% \mathrm{Cl} 1.3-2.3)$ were associated with MP. Risk factors for single-site pain and for subsequent musculoskeletal comorbidity were very similar, suggesting an additive effect of risk factors.

Conclusions: Most workers reported MP that was associated with several work-related factors. The findings support the idea that multisite pain is a continuum of single-site pain, maintained by exposure to several risk factors, rather than the result of a specific risk factor that initiates the multisite pain but not single-site pain. Workplace interventions are needed to decrease the number of pain sites, in order to improve the worker's health.

Keywords: Multi-site pain, Musculoskeletal, Pain, Neck, Upper limbs, Low back, Lower limbs, Co-morbidity, Widespread pain, Workload

\footnotetext{
* Correspondence: a.burdorf@erasmusmc.nl

${ }^{2}$ Department of Public Health, Erasmus MC, University Medical Center

Rotterdam, P.O. Box 20403000, CA, Rotterdam, The Netherlands

Full list of author information is available at the end of the article
} 


\section{Background}

The scientific literature in the past decades has shown the high prevalence of musculoskeletal disorders (MSD) in occupational populations, in industrialized and developing countries. MSD are also an important cause of sickness absence and, in Brazil, ranked the second most prevalent health problem for receiving social benefits for temporary and permanent disability [1].

The main approach applied to study MSD, in these past decades, is based on specific pain in one body site, such as neck pain, pain in upper limbs, and low back pain. Not only the descriptions of the prevalence of pain, as main indicator of MSD, but also the analysis of important determinants of these disorders, have been done according to this approach, i.e., by single site pain.

Nevertheless, in the past few years ago, some authors have discussed that most workers report pain in more than one body site. Several studies have described the presence of multisite pain (MP), both in industrial workers' population and among service workers [2-16]. There are also several studies showing the importance of this widespread pain in the general population [17-20].

The pioneer studies date from the early 2000s. Natvig et al. [17], found that low back pain along with widespread pain in the previous week was more common than localized back pain among general population in a municipality of Norway. Molano et al. [2], studying a population of scaffolders, discussed the co-morbidity between low back pain and musculoskeletal pain in other body sites. In these pioneer studies, it is hypothesized that "widespread pain could act as a marker of severity for LBP" [17] and "most of the workers not only had back pain but also another musculoskeletal complaint [2]. In 2002, Yeung et al. [3] found that "musculoskeletal symptoms for multiple body parts (two or more) were more prevalent (64\% of all workers) than those for single body regions (19\%). Approximately $85 \%$ of lower back symptoms were associated with disorders in other body regions." Morken et al. [4] found that widespread pain - in the previous 12 months - predicted shortterm and long-term sickness absence among industrial workers. Another study stated that many industrial workers with low back pain experienced musculoskeletal comorbidity in the past 12 months, which was related to a poorer general health and health related quality of life [5]. Alexopoulos et al. [6] reported a high concurrence of musculoskeletal disorders in dentists.

Since then, several studies have been conducted that demonstrated that musculoskeletal multimorbidity has a great impact on overall quality of health, activities of daily living, physical fitness, social activities, reduced work ability and sickness absence than single body segment pain [7-12, 18, 19]. Carnes et al. [19] stated that "of those with chronic musculoskeletal pain, only one in four have single-site pain. Single-site chronic pain is uncommon".
According to Kamaleri et al. [18], "most people having musculoskeletal pain reported pain from a number of sites" and with increased number of pain sites functional problems also increased.

High physical demands, like repetitive movements, awkward postures, heavy lifting, and psychosocial demands have been associated with Multisite Pain. Overweight or obesity and low leisure-time physical activities have been also found as risk factor to MP. Besides, women seems to be more prone to report pain in multiple body sites $[8,9,16,20]$.

In summary, there is clear evidence that multisite pain is much more common than single site pain. However, there is surprising few studies that have addressed underlying risk factors for multisite pain. Therefore, the aims of this study were (i) to estimate the prevalence of multisite pain, (ii) to describe the associations between pain in different body sites and (iii) to investigate related factors to multisite pain in workers from Bahia, Brazil.

\section{Methods \\ Study population}

In this cross sectional study, the study population comprised workers from shoe industry companies and workers from urban cleaning services in the state of Bahia, Brazil. These companies were selected for their willingness to provide access for research, the presence of physical demands at work, and being located in the vicinity of the university.

A total of 1070 workers participated in the study (response $97 \%)$. The study population comprised: a stratified random sample from two shoe industry's companies, proportional to the number of employees in each company and proportional to gender $(n=446)$, in Bahia, in 2012; all urban cleaning workers, the maintenance and operation staff, from the company that provides the service to Salvador City, Bahia, Brazil, in $2010(n=624)$. All participants were employed when the study was conducted. In the shoe industry the main occupations involved were assemblers or manufacturers of shoes and machine operators, and occupations in urban cleaning services were garbage collectors, truck drivers, and maintenance workers. In this study population, there is a set of different occupations and duties that varies from physically light duties ( $8 \%$ of workers), maintenance duties, performed walking or in standing posture, with occasional material handling (8\%), tasks predominantly performed in sitting posture with repetitive movements with hands or arms (23\%) to occupations highly physical-demanding, with frequent handling of heavy materials, while jumping, running or walking behind the truck (34\%), tasks requiring walking while cleaning beaches or urban areas, involving managing tools (8\%) and occupations in assemble lines, assembling and manufacturing shoes, involving a long working day in 
standing posture with repetitive movements with arms and hands, handling light materials (18\%).

To collect the data, interviews with a structured questionnaire were conducted, by a team of trained interviewers consisting of one health and safety engineer, three physiotherapists, one ergonomist and four academics from the physiotherapy course. They were aware about being sure of clarifying all questions.

Data were collected at each participating company, during a regular working day, in a reserved place, ensuring privacy to workers. Data collection was preceded by meetings with researchers and workers inside each company. The conversation aimed to introduce the research team, inform about the study objectives, about the institution in charge of the research, Federal University of Bahia, a public university, and about the fact that the companies were just contacted to allow the access to the work environment by researchers, but they did not have any participation in the study or access to individual data. This initiative was taken based on respect for the right to information of each research subject and to reduce the bias of information.

\section{Questionnaire}

The questionnaire included sociodemographic factors (age, gender), physical work demands and psychosocial demands, lifestyle habits, leisure-time physical activities and presence of musculoskeletal complaints.

Musculoskeletal complaints were measured by the enlarged version of Nordic Musculoskeletal Questionnaire (NMQ) [21, 22]. Studies of validity and reliability with the NMQ generally revealed high validity and reliability $[21,23,24]$. The questionnaire asked about the presence of pain in the previous 12 months and in the previous week before the interview, for each one of the following body sites: 1. upper limbs (hand, wrist, forearm, elbow), 2. neck, 3. shoulder, 4. upper back, 5. lower back, 6 . upper legs/knees, 7. lower legs, 8. Ankles/feet. Musculoskeletal Pain was defined as presence of pain in the previous seven days, considering the body sites mentioned above. Multisite pain was defined by the sum score of all body sites with pain, varying from zero to eight, i. e., based on the eight body sites above, individuals with no pain scored 0 , those with pain in one body site scored 1 and so on, up to score 8 for individuals with pain in all eight body sites.

Physical work demands were measured by means of workers' self-reports on a set of questions using a 6-point scale, ranging from 0 to 5 (scale of duration), with verbal qualifiers at the ends $(0=$ "never" and $5=$ "all the time"). Questions were asked about repetitive hand movements; general working postures like sitting, standing, walking; awkward postures like arms above shoulder height, trunk bent forward or trunk twisted, and squatting; material handling like weight lifting, pulling or pushing; and mechanical grip force on the object of work. For this last variable, we used a 6-point response scale on intensity and verbal qualifiers at the ends were "too weak" $=0$ and "too strong" $=5$. Factor analysis was carried out to identify underlying factors, reduce the number of variables and prevent variable redundancies.

Psychosocial aspects of work were measured by means of the Job Content Questionnaire (JCQ), with a four point scale, in the version translated into Portuguese and validated by Araújo and Karasek [25], whose Cronbach's alpha coefficients revealed acceptable internal consistency and factor analysis showed high consistency with the theoretical model. According to this Karasek model [26], workers are supposedly at risk when under high job demands and low job control. Besides, experiencing low social support, either from colleagues or supervisors, will increase health risk. Job demands were measured by nine questions, related to working fast, working hard, excessive work, insufficient time to complete the work, and conflicting demands. Job control was measured by six questions on skills and three questions on authority to make decisions, i.e., nine questions in total. These questions regarded aspects such as required skills, task variety, learning new things, and amount of repetitive work. Sum scores across job control and job demands were dichotomized at median scores to define high strain (high demand and low control). Besides, social support was analyzed by combining both variables, support from colleagues and from supervisors, in one variable, dichotomized by median scores.

With regard to leisure-time physical activities, interviewers asked individuals about what they usually do while not working in the company or at home. This question had a four-item response scale: 1 . Competitive sports activity, 2. Running, doing gymnastics, swimming, playing football, bike riding, 3. Walking, fishing and gardening, 4. Reading the newspaper or a magazine, watching television and studying. Individuals with answers 1, 2 or 3 were considered as "active" in leisure-time.

Body Mass Index (BMI, $\mathrm{Kg} / \mathrm{m}^{2}$ ) was calculated based on direct measurements of height and weight done by interviewers. It was considered as low weight $<18.5$, normal $18.5-25$, overweight $>=25-30$ and obesity $>=30 \mathrm{~kg} / \mathrm{m}^{2}$. A dichotomized variable was used: normal $<25$ or overweight/obesity $>=25$.

\section{Statistical analysis}

The statistical analysis consisted of several steps. First, a factor analysis was performed that captured the nine variables of physical exposure into two latent factors that explained $63 \%$ of the total variance. The initial extraction was made through the main components of the model, and factors were obtained without rotation. Their composition, in a decreasing order of the loads presented by 
each variable, was as follows: Factor 1 (Initial Eigenvalue $=4.494 ;$ variance $=49.9 \%$ ) characterized physical demands of material handling and strenuous postures including awkward postures: pulling, lifting and pushing weights, squatting, arms above shoulder height, trunk bending, trunk rotation, mechanical hand pressure on the object of work. Factor 2 (Initial Eigenvalue $=1.186$; variance $=$ $13.2 \%)$ characterized repetitive work with the variable "repetitive hand movements". Both factors were used as independent variables for physical work demands with cut-off point at third quartile values.

In the second step, musculoskeletal multisite pain was described, estimating its prevalence and describing the proportions of concurrent pain for each one of the eight body sites. The associations between pain in different body sites were assessed, presenting the prevalence ratio (PR) as measure of association and $95 \%$ confidence interval.

In the third step, Cox regression analyses were performed to investigate the factors associated with multisite pain. The PR is a better approximation of the risk than the often-used odds ratio in a situation with a high prevalence of disease. The Cox regressions consisted of three different models. In the first model, multisite pain is compared with no pain. In the second model singlesite pain is compared with no pain and in the third model, multisite pain is compared with single-site pain. All models were adjusted for age, gender, body mass index, physical demands at work, psychosocial work demands and leisure-time physical activities. The differences between these three models allow interpretation on the absence or presence of synergistic effects of risk factors, i.e., without synergy the influence of a particular risk on multisite pain (model 1) would equal the combined effect of that risk factor on single-site pain (model 2) and on subsequent multisite pain (model 3).

The logistic regression analysis is widely used in cross sectional studies and provides odds ratios estimates. Odds Ratios typically overestimate the associations for outcomes that are frequent, such as MSD. So, we conducted Cox regression analysis, based on Coutinho et al. [27], in order to provide Prevalence Ratio estimates. In analyses of data from cross-sectional studies, the Cox and Poisson models with robust variance are better alternatives than logistic regression analysis. Besides, these authors have shown that if in cross sectional studies a constant risk period is assigned to all the individuals in the study, the hazard ratio in Cox regression analysis equals the PR.

The use of statistical estimation in this study is only aimed at showing the precision of estimation, by means of the confidence intervals of $95 \%$. Our study population is not a random sample, so, the inferential statistics presented serves merely "as a minimum estimates of the actual uncertainty about the object of estimation" [28]. We assume a critical view about statistical inference, given the common misinterpretation of statistical information [28, 29].

All descriptive and inferential statistical analyses were performed using the SPSS software, Version 21.

\section{Results}

The study population of 1070 workers comprises 228 women and 842 men, with a mean age of 31 years (25th percentile $=26$ years, 75 th percentile $=37$ years )

Table 1 shows that the prevalence of musculoskeletal pain varied from $10.4 \%$ for ankle/feet to $23.8 \%$ for lower back. The prevalence of single-site pain without any musculoskeletal co-morbidity was much lower, varying between $1.1 \%$ for neck pain to $6.6 \%$ for lower back pain. For all body sites, musculoskeletal co-morbidity was high. Among those with neck pain, $43.7 \%$ had concurrent pain in upper back and $34 \%$ had shoulder pain. In total, the proportion of neck pain concurrent with pain in at least one other site is $90.5 \%$, i.e., almost all workers with neck pain reported pain in another body site. The same pattern was observed for other musculoskeletal complaints.

Table 1 Co-occurrence of pain based on conditional proportions of pain in previous seven days, among industrial workers and urban cleaning service workers, Bahia, Brazil

\begin{tabular}{|c|c|c|c|c|c|c|c|c|c|c|c|c|}
\hline \multirow[t]{2}{*}{ Body site } & \multicolumn{2}{|c|}{ Prevalence } & \multicolumn{2}{|c|}{ No pain in other sites } & \multicolumn{8}{|c|}{ Concurrent pain during the previous seven days (\%). Conditional proportions. } \\
\hline & $n$ & $\%$ & $n$ & $\%$ & Neck & Shoulder & Upper back & Upper limbs & Low back & Upper leg/knee & Lower Leg & Ankle/Feet \\
\hline Neck & 126 & 11.8 & 12 & 1.1 & - & 34.1 & 43.7 & 41.3 & 53.2 & 28.6 & 40.5 & 27.8 \\
\hline Shoulder & 131 & 12.2 & 22 & 2.1 & 32.8 & - & 38.2 & 39.7 & 51.9 & 29.8 & 35.1 & 29.0 \\
\hline Upper back & 151 & 14.1 & 25 & 2.3 & 36.4 & 33.1 & - & 37.7 & 50.3 & 31.8 & 40.4 & 27.2 \\
\hline Upper limbs & 198 & 18.5 & 47 & 4.4 & 26.3 & 26.3 & 28.8 & - & 39.9 & 27.8 & 36.4 & 24.2 \\
\hline Low back & 255 & 23.8 & 71 & 6.6 & 26.3 & 26.7 & 29.8 & 31.0 & - & 27.1 & 28.6 & 20.8 \\
\hline Upper leg/ knee & 151 & 14.1 & 32 & 3.0 & 23.8 & 25.8 & 23.8 & 36.4 & 45.7 & - & 37.7 & 33.1 \\
\hline Lower Leg & 173 & 16.2 & 28 & 2.6 & 29.5 & 26.6 & 35.3 & 41.6 & 42.2 & 32.9 & - & 37.0 \\
\hline Ankle/Feet & 111 & 10.4 & 16 & 1.5 & 31.5 & 34.2 & 36.9 & 43.2 & 47.7 & 45.0 & 57.7 & - \\
\hline
\end{tabular}


In the previous seven days, $23.6 \%$ of workers had single-site pain and $30.1 \%$ of workers had pain in more than one site. Among those who had pain, $56.0 \%$ had pain at least in two sites (Table 2).

For all eight body sites, musculoskeletal comorbidity was high, varying between $72.2 \%$ for lower back to $90.5 \%$ for neck pain. Many workers with musculoskeletal comorbidity reported pain in more than three sites (Table 3).

Table 4 shows that having pain in one body site is associated with pain in other site. For example, the prevalence of neck pain among who had shoulder pain was 3.7 times that prevalence among those without the shoulder pain. The associations between proximal sites were stronger than between more distal sites with pooled PRs of 3.75 and 2.87, respectively. For example, the association between lower leg pain and ankle/feet pain $(\mathrm{PR}=7.1)$ was higher than lower back pain with ankle/feet pain $(P R=2.9)$. Likewise, upper back pain had a stronger association with neck pain (4.7) than with upper limbs pain ( $P R=2.5)$.

In the first model, being highly exposed to physical work demands, i.e. to manual material handling and awkward postures, increased 1.5 fold the prevalence of multisite pain (95 \% CI 1.1-2.0). Job strain (PR $=1.2,95 \%$ CI 1.0-1.6) and low social support (PR $=1.3,95 \%$ CI 1.0-1.7) were other occupational factors positively associated with having pain in at least two sites of the body. Women ( $P R=1.7$, $95 \%$ CI 1.3-2.3) more often had multisite pain than men. The comparison with the second and third model showed that the risk factors for multisite pain are primarily an additive effect of the risk for having a single-site pain (model 2) and the risk for a subsequent comorbidity (model 3). The observed associations for risk factors with single-site pain and with subsequent comorbidity were very similar, also suggesting an additive effect of risk factors (Table 5).

Table 2 Prevalence of pain by number of sites in previous seven days, among industrial workers and urban cleaning service workers, Bahia, Brazil

\begin{tabular}{llll}
\hline Number of & \multicolumn{3}{l}{ Pain in the previous seven days } \\
\cline { 2 - 4 } Body Sites & $\mathrm{n}$ & $\%$ & Cumulative percent \\
\hline None & 495 & 46.3 & 46.3 \\
Single & 253 & 23.6 & 69.9 \\
Two & 135 & 12.6 & 82.5 \\
Three & 87 & 8.1 & 90.7 \\
Four & 47 & 4.4 & 95.0 \\
Five & 19 & 1.8 & 96.8 \\
Six & 16 & 1.5 & 98.3 \\
Seven & 11 & 1.0 & 99.3 \\
Eight & 7 & 0.7 & 100.0 \\
Total & 1070 & 100.0 & \\
\hline
\end{tabular}

Table 3 Distribution of single-site pain and multisite pain among those with any musculoskeletal complaint in the previous seven days, among industrial workers and urban cleaning service workers, Bahia, Brazil

\begin{tabular}{lccc}
\hline Body site & \multicolumn{3}{l}{ Number of pain sites } \\
\cline { 2 - 4 } & \multicolumn{1}{c}{$\%$} & $2-3$ & $>4$ \\
& $\%$ & 46.9 & 43.6 \\
\hline Neck & 9.5 & 38.2 & 45.0 \\
Shoulder & 16.8 & 39.8 & 43.6 \\
Upper back & 16.6 & 42.4 & 33.9 \\
Upper limbs & 23.7 & 42.0 & 30.2 \\
Low back & 27.8 & 39.7 & 39.1 \\
Upper leg/ knee & 21.2 & 42.2 & 41.6 \\
Lower Leg & 16.2 & 34.2 & 51.4 \\
Ankle/Feet & 14.4 & & \\
\hline
\end{tabular}

\section{Discussion}

The aims of this study were to estimate the prevalence of multisite pain, to describe the associations between pain in different body sites and to investigate related factors to multisite pain in workers from Bahia, Brazil. We found that in the previous seven days, one third of workers had multisite pain and having pain in one site was highly associated with pain in another body site. Workers under high exposure to physical demands at work, such as manual material handling and strenuous postures, had the highest prevalence of pain, regardless being men or women.

The study was conducted in workplaces during working days, in which the workers were interviewed about multisite body pain. In those days, they were performing their tasks, either in cleaning urban services or in the shoe factories. This study corroborates that concurrent musculoskeletal pain is higher than single-site pain for all body sites in the short time period of seven days. For every pain site there was at least one other site of pain in a proportion of $72 \%$ up $90 \%$. This finding is compatible to Kamaleri et al. [18], who stated that "for every pain site more than $85 \%$ had pain from at least one other region". The results showed a much higher proportion of concurrent pain than single site-pain, hence, single-site pain seems to be a rare outcome among workers. This was also observed in the general population, where multisite pain seems to be much more frequent than a single-site pain [19]. In this latter study among adults registered with general practitioners in England, the prevalence of single-site pain in the past 12 months was very low, like in the present study, ranging from 1 to $3 \%$ versus 1 to $7 \%$ in our study.

Comparisons between our findings and those by Kamaleri et al. [18], who assessed pain for the same period of time, i.e., seven days, reveal that proportion of 
Table 4 Prevalence ratios (PR) of pain in a site relative to another in previous seven days, among industrial workers and urban cleaning service workers, Bahia, Brazil

\begin{tabular}{|c|c|c|c|c|c|c|c|c|}
\hline Site & $\mathrm{Neck}^{\mathrm{a}}$ & Shoulder $^{a}$ & Upper back ${ }^{\mathrm{a}}$ & Upper limbs $^{a}$ & Low back ${ }^{a}$ & Upper leg/knee & Lower leg $^{a}$ & Ankle/Feet $^{a}$ \\
\hline $\mathrm{Neck}^{\mathrm{b}}$ & - & $3.7(2.7-5.0)$ & $4.3(3.3-5.6)$ & $2.7(2.1-3.4)$ & $2.7(2.2-3.3)$ & $2.3(1.7-3.2)$ & $3.1(2.4-4.1)$ & $3.4(2.4-4.9)$ \\
\hline Shoulder ${ }^{b}$ & $3.7(2.7-5.1)$ & - & $3.5(2.7-4.7)$ & $2.5(2.0-3.3)$ & $2.6(2.1-3.2)$ & $2.5(1.8-3.4)$ & 2.6(1.9-3.4) & $3.7(2.6-5.3)$ \\
\hline Upper back ${ }^{\mathrm{b}}$ & $4.7(3.5-6.4)$ & $3.8(2.8-5.1)$ & - & $2.5(1.9-3.2)$ & $2.6(2.1-3.2)$ & $2.8(2.1-3.8)$ & $3.3(2.5-4.3)$ & $3.6(2.5-5.0)$ \\
\hline Upper limbs ${ }^{b}$ & $3.1(2.2-4.3)$ & $2.9(2.1-4.0)$ & $2.7(2.0-3.6)$ & - & $2.0(1.6-2.4)$ & $2.5(1.9-3.4)$ & $3.1(2.4-4.1)$ & $3.3(2.4-4.7)$ \\
\hline Low back & $3.6(2.6-5.0)$ & $3.4(2.5-4.7)$ & $3.2(2.4-4.3)$ & $2.1(1.7-2.7)$ & - & $2.7(2.0-3.6)$ & $2.3(1.8-3.0)$ & $2.9(2.1-4.1)$ \\
\hline Upper leg/knee & $2.4(1.7-3.4)$ & $2.6(1.8-3.6)$ & $2.8(2.1-3.8)$ & $2.3(1.8-3.0)$ & $2.3(1.8-2.8)$ & - & $3.0(2.3-3.9)$ & $5.0(3.6-6.9)$ \\
\hline Lower Leg $^{\text {b }}$ & $3.5(2.6-4.8)$ & $2.8(2.0-3.9)$ & $3.5(2.6-4.7)$ & $3.0(2.3-3.8)$ & $2.1(1.7-2.6)$ & $3.1(2.4-4.2)$ & - & $7.1(5.0-9.9)$ \\
\hline Ankle/Feet ${ }^{\mathrm{b}}$ & $3.3(2.4-4.6)$ & $3.5(2.6-4.9)$ & $3.2(2.4-4.3)$ & $2.8(2.1-3.6)$ & $2.3(1.8-2.8)$ & $4.3(3.2-5.6)$ & $5.1(4.0-6.4)$ & - \\
\hline
\end{tabular}

$\mathrm{PR}(95 \% \mathrm{Cl}) .{ }^{\mathrm{a}}$ Treated as the dependent variable. ${ }^{\mathrm{b}}$ Treated as the independent variable

single site pain is equally much lower than that of multisite pain.

The high proportion of concurrent pain, based on eight separated body sites, might be the consequence of the high prevalence of pain in different sites. Croft et al. [30] state that associations between pain complaints will inevitably occur because of the underlying frequency of the individual syndromes. To those authors, no one "should expect that any specific concurrence would happen more often than expected (...) given that any pain is more likely to occur in the presence of another pain, whatever the location of pain: anyone setting out to study a particular association between two pain syndromes can be both reassured (you will find it) and cautioned (there will be nothing special about the result)". Our results are compatible with this statement, in the sense that the prevalence of concurrent pain was high for every pain site. The prevalence ratios were high regarding the association among pain in different sites, i. e., having pain in one site was associated with an increased occurrence of pain at another site. We did find various associations between two pain-sites, and, in general, proximal sites were higher associated than distal ones.
Haukka et al. [12], who analyzed associations between pain in different body sites among female workers, found that the prevalence of neck pain among those who had back pain to be 1.4 times the prevalence of neck pain among those without back pain and the association was 1.6 times among back pain and upper limbs' pain. Alexopoulos et al. [6], studying female and male dentists, found that having low back pain resulted in 3 fold chance of having neck pain and 2.4 fold chance of having pain in hand/wrist. These latter results are very similar to ours, 3.6 and 2.1, respectively.

Several studies have discussed the presence of concurrent musculoskeletal pain and its repercussion on health related quality of life, on sick leave $[5,11,13,18]$ and on loss of productivity or work disability $[7,10,14,15]$. However, less is known about determinants of this multimorbidity, particularly, concerning the role of occupational factors and, mainly, what determines single or multisite pain.

According to our findings, having concurrent pain, i.e., presenting a multisite pain, was associated with being exposed to high physical demands at work. Also, we found a contribution of low job support to the occurrence of multisite pain and working under high psychological demand

Table 5 Multivariate analysis of related factors to multisite and single-site pain in previous seven days among industrial workers and urban cleaning service workers, Bahia, Brazil

\begin{tabular}{llll}
\hline Associated factors & $\begin{array}{l}\text { Multisite pain vs No } \\
\text { pain }(n=759) \\
\text { PR 95\% Cl }\end{array}$ & $\begin{array}{l}\text { Single-pain vs No } \\
\text { pain }(n=693)\end{array}$ & $\begin{array}{l}\text { Multisite pain vs Single-site } \\
\text { pain }(n=538) \\
\text { PR 95\% Cl }\end{array}$ \\
\hline High exposure to material handling and awkward postures & $1.5(1.1-2.0)$ & $1.2(0.8-1.6)$ & $1.3(0.9-1.7)$ \\
High repetitive movements & $1.2(0.9-1.6)$ & $1.2(0.8-1.6)$ & $1.1(0.8-1.4)$ \\
High strain: High psychological demand and low job control & $1.2(1.0-1.6)$ & $1.2(0.9-1.7)$ & $1.0(0.8-1.3)$ \\
Low social support & $1.3(1.0-1.7)$ & $1.3(1.0-1.7)$ & $1.0(0.8-1.3)$ \\
Gender: female & $1.7(1.3-2.3)$ & $1.4(1.0-2.0)$ & $1.3(0.9-1.7)$ \\
Overweight & $1.1(0.9-1.4)$ & $1.2(0.9-1.6)$ & $0.9(0.8-1.2)$ \\
Above 37 yrs & $0.9(0.7-1.2)$ & $0.9(0.7-1.2)$ & $1.0(0.8-1.3)$ \\
No leisure-time physical activity & $1.0(0.8-1.3)$ & $1.0(0.8-1.4)$ & $1.0(0.8-1.3)$ \\
\hline
\end{tabular}


without a good job control increased the prevalence of having multisite pain.

The high prevalence of multisite pain in our population is compatible with findings of studies among different occupational groups, like kitchen workers [12] or food industry workers [15] or dentists [6], and compatible with results in the general population $[18,19]$. This main finding of our study indicates that single site pain is a rare condition compared to concurrent pain. This supports the idea that when considering different patterns of exposure to physical demands at work, one should bear in mind that the occurrence of musculoskeletal pain most often will not be localized in one specific site. Hence, exposure-response relationships may be less specific than observed. It is important to consider the questions raised by Croft at al. [30] about the nature of central pain and pain processing, and about the plastic memory of the nervous system for pain that operates independently of the initial site of nociceptive stimulus. This theory of central pain is helpful to explain why the associations between pain in different body locations, whatever is the location, were always strong according to our results.

The workers in our study are exposed to a diversity of physical demands at work. Our study population comprises many occupations: office workers in shoe manufacturing companies, assemblers or manufacturers of shoes and machine operators, garbage collectors, truck drivers, and maintenance workers. The tasks performed by workers involve pulling, lifting and pushing weights, squatting, arms above shoulder height, trunk bending, trunk rotation, mechanical hand pressure on the object of work, and, for most of workers, a high exposure to repetitive hand movements. The diversity of physical demands in our population and different patterns of exposure may be an important reason for presence of multisite pain.

In this study, with a high prevalence of multisite pain in the last seven days, the pattern of physical demands exposure among workers varied from more localized physical demand on specific body sites to uniformly distributed physical demands on the total body as described above. Regardless the set of different pattern of physical exposure, our results are compatible with studies in specific occupations, such as Haukka et al. [12] who reported in a study among female kitchen workers also a high prevalence of multisite pain. Alexopoulos et al. [6] studied dentists, also a specific occupation, and found a high prevalence of concurrent pain. It is possible to say that the pattern of physical demands at work for a dentist is very different of the exposure pattern of a worker in dynamic work, with handling heavy materials in cleaning services. Therefore, there is no single or obvious explanation to the high prevalence of multisite pain as a direct consequence of physical work load on the painful body sites. Hence, we share the discussion by Croft et al. [30] based on two important explanations of the high occurrence of multisite pain: first, a general vulnerability related to the central pain processing, and, second, shared risk factors that concern the role of physical demands at work that simultaneously act at more than one body site

It is hypothesized that based on the shared biomechanical risks, or physical exposure, occupational situations are more frequently demanding for a body region involving closer sites, at least, closer sites will be firstly reached by damages. Even though, dependent on the physical demands pattern, we can expect not only association among pain in closer sites but also association among farther ones. For example, pain in lower back and shoulder pain might be associated when both body sites experience high mechanical load. Another example is the large amount of tasks performed on countertops or tables (on assembly lines) that involves standing posture and neck bending or holding head bent forward - this fact can result in high physical demands to lower limbs, but, at the same time, it results in neck and upper back demanding. So, not only the closest body sites but also the farthest sites will be affected as consequences of the exposure to physical demands.

In an earlier prospective study, Macbeth et al. [31] investigated related factors to widespread pain in adults, selected from a population-based primary care register. They presented evidence of an association between repetitive movements with wrists, pushing/pulling heavy weights and kneeling with widespread pain. Harkness et al. [32] found associations between pulling load, squatting, monotonous work, and low support from colleagues with the presence of widespread chronic pain.

Neupane et al. [16], reported associations between multisite pain and repetitive work and awkward posture. Besides, they found a role of the job dissatisfaction and of the poor opportunities to exert influence on executing work activities. Strenuous physical activities were associated with multisite pain in study by Solidaki et al. [8] Haukka et al. [9] found that perceived physical workload and adverse psychosocial factors at work were also associated with multisite pain.

Those former findings support the results of the current study. The contribution of our study is not only in demonstrating the presence of the high magnitude of multisite pain, even in a short time window like the previous week which present reliable information about concurrent pain, but also in illustrating the important role of work conditions for multisite pain. Beyond, the findings support the idea that multisite pain is a continuum of single-site pain, maintained by exposure to several risk factors, rather than the result of a specific risk factor that initiates the multisite pain but not single-site pain. So, our results are compatible with the statement by Croft [33] about considering 
"number of pain sites as a continuously distributed marker of risk for poor health outcomes".

There is some evidence about the association between gender and multisite pain. The female population not only has a high prevalence of musculoskeletal pain, but they also seem to report more sites with pain than the male population. The role of gender in determining widespread pain in persons with low back pain has been highlighted since 2001, by Natvig et al. [17], in a study with a general population, and by Carnes et al. [19], who found $20 \%$ less multisite pain among men than among female people. That is compatible with our finding that women more often had multisite pain than men.

The literature refers about the role of somatization to predict chronic widespread pain but this finding is not consistent among studies. Some authors state that most of subjects with multisite pain are not 'somatizers' [10]. In studies that have shown associations of somatization with multisite pain, the importance of physical work demands as independent risk factor for musculoskeletal multisite pain has been confirmed $[8,31]$.

Prevalence of musculoskeletal pain in different body sites will be higher when the recall period of pain is higher. In a longer period of time, the reports of pain from more than one body site (multisite pain) can represent, in the truth, different episodes of pain occurring in different time, instead of being concurrent pain. Since this study aimed to describe multisite pain, the previous seven days may represent a more appropriate period of time to measure simultaneous pain occurrence.

Some strengths of this study, in spite of its cross sectional design, are related to strategies adopted in order to minimize the information bias. Taking into account the context of labor relations in Brazil, the methods applied in our study ensured absolute privacy and confidentiality and information was collected by independent researchers. This will have facilitated the high participation and the trust of workers in the public and respectful institution responsible for the study (Federal University of Bahia). Besides, doing the data collection by means of interviewer-administered questionnaire with a highqualified team, conscious about interview techniques, work context, labor relations, cultural and linguistic issues of labor environment, contributed to the high response. Moreover, to collect data by means of interview can be a strong point of our study, in order to avoid information bias, because we could clarify any item of the questionnaire when necessary, what certainly improved the quality of workers' responses. Interviewers had to make sure that workers had understood all information about confidentiality, trying to clarify all possible questions regarding the questionnaire and obtaining the best responses. In spite of the sample size of this study, all these procedures were thoroughly performed.

\section{Conclusions}

Multisite pain has a high magnitude among workers. It affects the daily life of workers and is associated with manual material handling and strenuous body postures in a demanding psychosocial workplace. The findings support the idea that multisite pain is a continuum of single-site pain, maintained by exposure to several risk factors, rather than the result of a specific risk factor that initiates the multisite pain, but not single-site pain. Workplace interventions, with an appropriate approach also regarding the role of gender on this morbidity, are needed in order to decrease the number of pain sites and to improve the quality of life at work. For future studies, it is advisable to not solely focus on musculoskeletal pain in one specific body site. It seems promising measuring multisite pain and to analyze the associated factors, and its consequences related to sickness absence and work ability.

\section{Abbreviations}

BMI, body mass index; JCQ, job content questionnaire; MP, multisite musculoskeletal pain; MSD, musculoskeletal disorders; NMQ, nordic musculoskeletal questionnaire

\section{Acknowledgments}

The first author is financially supported by Coordenação de Aperfeiçoamento de Pessoal de Nível Superior - CAPES, Brazil, that allowed her to be a visiting researcher at Erasmus-MC Rotterdam, the Netherlands (Grant number: 6476-14-7) The authors thank Adilton Pio, Rives Borges, Cléber Gomes, Verônica Cadena Lima, as well as The State Center of Reference for Worker Health (CESATSUS-Bahia).

\section{Availability of data and materials}

The dataset that supports the conclusions of this article is under the responsibility of the authors. Data will not be shared because the informed consent was not obtained for data sharing.

\section{Authors' contributions}

RCPF participated in the design of the study, drafted the manuscript, performed the statistical analysis and the interpretation of data. SMSP participated in the acquisition and in checking the data, and revised the manuscript critically. RBC participated in the acquisition and in checking the data. $A B$ participated in the design of the study, participated in the interpretation of data and in writing the manuscript, revising it critically. All authors read and approved the final version.

\section{Competing interests}

The authors declare that they have no competing interests.

\section{Consent for publication}

Not applicable.

\section{Ethics approval and consent to participate}

The Research Ethics Committee of Hospital São Rafael (Number: 48/09) and of Escola de Enfermagem da Universidade Federal da Bahia (48/11) approved the study proposals. Each worker signed an informed consent form before answering the questionnaire.

\section{Author details}

${ }^{1}$ Departamento de Medicina Preventiva e Social, Faculdade de Medicina da Bahia, Universidade Federal da Bahia, Largo do Terreiro de Jesus, s/n. Centro Histórico, 40.026-010 Salvador, Bahia, Brazil. ²Department of Public Health, Erasmus MC, University Medical Center Rotterdam, P.O. Box 20403000, CA, Rotterdam, The Netherlands.

Received: 21 April 2016 Accepted: 14 July 2016

Published online: 22 July 2016 


\section{References}

1. Almeida PCA, Barbosa-Branco A. Acidentes de trabalho no Brasil: prevalência, duração e despesa previdenciária dos auxílios-doença. Rev bras Saúde ocup, São Paulo. 2011;36(124):195-207.

2. Molano SM, Burdorf A, Elders LAM. Factors associated with medical careseeking due to low-back pain in scaffolders. Am J Ind Med. 2001:40:275-81.

3. Yeung SS, et al. Prevalence of musculoskeletal symptoms in single and multiple body regions and effects of perceived risk of injury among manual handling workers. SPINE Change SPINE into Spine. 2002;27(19):2166-72.

4. Morken T, Riise T, Moen B, Hauge SHV, Holien S, Langedrag A, Pedersen S, Saue ILL, Seljebø GM, Thoppil VT. Low back pain and widespread pain predict sickness absence among industrial workers. BMC Musculoskelet Disord. 2003:4:21.

5. ljzelenberg W, Burdorf A. Impact of musculoskeletal co-morbidity of neck and upper extremities on healthcare utilisation and sickness absence for low back pain. Occup Environ Med. 2004;61(10):806-10.

6. Alexopoulos EC, Stathi I-C, Charizani F. Prevalence of musculoskeletal disorders in dentists. BMC Musculoskelet Disord. 2004;5:16.

7. Neupane S, Virtanen P, Leino-Arjas P, Miranda H, Siukola A, Nygard C-H. Multi-site pain and working conditions as predictors of work ability in a 4year follow-up among food industry employees. Eur J Pain. 2013;17:444-51.

8. Solidaki E, Chatzi L, Bitsios P, Coggon D, Palmer KT, Kogevinas M. Risk factors for new onset and persistence of multi-site musculoskeletal pain in a longitudinal study of workers in Crete. Occup Environ Med. 2013;70:29-34.

9. Haukka E, Ojajarvi A, Takala E-P, Viikari-Juntura E, Leino-Arjas P. Physical workload, leisure-time physical activity, obesity and smoking as predictors of multisite musculoskeletal pain. A 2-year prospective study of kitchen workers. Occup Environ Med. 2012;69:485-92.

10. Miranda H, Kaila-Kangas L, Heliovaara M, Leino-Arjas P, Haukka E, Liira J, Viikari-Juntura E. Musculoskeletal pain at multiple sites and its effects on work ability in a general working population. Occup Environ Med. 2010;67:449-55.

11. Nyman T, Grooten WJA, Wiktorin C, Liwing J, Norrman L. Sickness absence and concurrent low back and neck-shoulder pain: results from the MUSIC - Norrtalje study. Eur Spine J. 2007;16:631-8.

12. Haukka E, Leino-Arjas P, Solovieva S, Ranta R, Viikari-Juntura E, Riihimaki H. Co-occurrence of musculoskeletal pain among female kitchen workers. Int Arch Occup Environ Health. 2006;80:141-8.

13. Neupane S, Leino-Arjas $P$, Nygard $C-H$, Miranda H, Siukola A, Virtanen P. Does the association between musculoskeletal pain and sickness absence due to musculoskeletal diagnoses depend on biomechanical working conditions? Int Arch Occup Environ Health. 2015:88:273-9.

14. Kamaleri Y, Natvig B, Ihlebaek CM, Bruusgaard D. Does the number of musculoskeletal pain sites predict work disability? A 14-year prospective study. Eur J Pain. 2009;13:426-30.

15. Neupane S, Miranda H, Virtanen P, Siukola A, Nygard C-H. Multi-site pain and work ability among industrial population. Occup Med. 2011;61(8):563-9.

16. Neupane S, Miranda H, Virtanen P, Siukola A, Nygard C-H. Do physical or psychosocial factors at work predict multi-site musculoskeletal pain? A 4year follow-up study in an industrial population. Int Arch Occup Environ Health. 2013:86:581-9.

17. Natvig B, Bruusgaard D, Eriksen W. Localized low back pain and low back pain as part of widespread pain musculoskeletal pain: two different disorders? A cross-sectional population study. J Rehabil Med. 2001;33:21-5.

18. Kamaleri Y, Natvig B, Ihlebaek CM, Bruusgaard D. Localized or widespread musculoskeletal pain: Does it matter? Pain. 2008;138:41-6.

19. Carnes D, Parsons S, Ashby D, Breen A, Foster NE, Pincus T, Vogel S, Underwood M. Chronic musculoskeletal pain rarely presents in a single body site: results from a UK population study. Rheumatology. 2007:46:1168-70.

20. Kamaleri Y, Natvig B, Ihlebaek CM, Benth JS, Bruusgaard D. Number of pain sites is associated with demographic, lifestyle, and health-related factors in the general population. Eur J Pain. 2008;12:742-8.

21. Kuorinka I, Jonsson B, Kilbom A, Vinterberg H, Biering-Sorensen F, Andersson G, Jorgensen K. Standardized Nordic questionnaires for the analysis of musculoskeletal symptoms. Appl Ergon. 1987;18(3):233-7.

22. Kuorinka I, Forcier L. Work related musculoskeletal disorders (WMSDs): a reference book for prevention. London: Taylor \& Francis; 1995.

23. Baron S, Hales T, Hurrel J. Evaluation of symptom surveys for occupational musculoskeletal disorders. Am J Ind Med. 1996;29:609-17.
24. Pinheiro FA, Troccoli BT, Carvalho CV. Validação do Questionário Nórdico de Sintomas Osteomusculares como medida de morbidade. Rev Saude Publica. 2002;36:307-12

25. Araújo TM, Karasek R. Validity and reliability of the job content questionnaire in formal and informal jobs in Brazil. Scand J Work Environ Health Suppl. 2008;6:52-9.

26. Karasek R. Job demand, job decision latitude, and mental strain: implications for job redesign. Adm Sci Q. 1979;24:285-308.

27. Coutinho LMS, Scazufca M, Menezes PR. Methods for estimating prevalence ratios in cross sectional studies. Rev Saude Publica. 2008;42(6):992-8.

28. Rothman KJ, Greenland S, Lash TL. Precision and statistics in epidemiologic studies. Modern Epidemiology. 3rd ed. Philadelphia, PA: Lippincott Williams \& Wilkins; 2008

29. Rothman KJ. Six persistent research misconceptions. J Gen Intern Med. 2014:29:1060-4.

30. Croft P, Dunn KM, Von Korff M. Chronic pain syndromes: you can't have one without another. Pain. 2007:131:237e8.

31. McBeth J, Harkness EF, Silman AJ, Macfarlane GJ. The role of workplace lowlevel mechanical trauma, posture and environment in the onset of chronic widespread pain. Rheumatology. 2003;42:1486-94.

32. Harkness EF, Macfarlane GJ, Nahit E, Silman AJ, McBeth J. Mechanical injury and psychosocial factors in the work place predict the onset of widespread body pain. A two-year prospective study among cohorts of newly employed workers. Arthritis \& Rheumatism. 2004:50(5):1655-64.

33. Croft P. The question is not "have you got it"? But "how much of it have you got"? Pain. 2009;141:6-7.

\section{Submit your next manuscript to BioMed Central and we will help you at every step:}

- We accept pre-submission inquiries

- Our selector tool helps you to find the most relevant journal

- We provide round the clock customer support

- Convenient online submission

- Thorough peer review

- Inclusion in PubMed and all major indexing services

- Maximum visibility for your research

Submit your manuscript at www.biomedcentral.com/submit

) Biomed Central 